\title{
The Central Nucleus of the Amygdala and Corticotropin- Releasing Factor: Insights into Contextual Fear Memory
}

\author{
Matthew W. Pitts, ${ }^{1}$ Cedomir Todorovic, ${ }^{2}$ Thomas Blank, ${ }^{2}$ and Lorey K. Takahashi ${ }^{1,3}$ \\ ${ }^{1}$ Department of Cell \& Molecular Biology and ${ }^{2}$ Specialized Neuroscience Research Project 2, John A. Burns School of Medicine, University of Hawaii, \\ Honolulu, Hawaii 96813, and ${ }^{3}$ Department of Psychology, University of Hawaii, Honolulu, Hawaii 96822
}

The central nucleus of the amygdala $(\mathrm{CeA})$ has been traditionally viewed in fear conditioning to serve as an output neural center that transfers conditioned information formed in the basolateral amygdala to brain structures that generate emotional responses. Recent studies suggest that the CeA may also be involved in fear memory consolidation. In addition, corticotropin-releasing factor systems were shown to facilitate memory consolidation in the amygdala, which contains a high density of CRF immunoreactive cell bodies and fibers in the lateral part of the $\mathrm{CeA}(\mathrm{CeAl})$. However, the involvement of CeA CRF in contextual fear conditioning remains poorly understood. Therefore, we first conducted a series of studies using fiber-sparing lesion and reversible inactivation methods to assess the general role of the $\mathrm{CeA}$ in contextual fear. We then used identical training and testing procedures to compare and evaluate the specific function of CeA CRF using CRF antisense oligonucleotides (CRF ASO). Rats microinjected with ibotenic acid, muscimol, or a CRF ASO into the CeA before contextual fear conditioning showed typical levels of freezing during acquisition training but exhibited significant reductions in contextual freezing in a retention test $48 \mathrm{~h}$ later. Furthermore, CeA inactivation induced by either muscimol or CRF ASO administration immediately before retention testing did not impair freezing, suggesting that the previously observed retention deficits were caused by inhibition of consolidation rather than fear expression. Collectively, our results suggest CeA involvement in the consolidation of contextual fear memory and specifically implicate CeA CRF as an important mediator.

\section{Introduction}

The amygdala plays an essential role in emotional learning and memory, which is investigated extensively using pavlovian fear conditioning. This procedure involves pairing a conditioned stimulus (CS) with an aversive unconditioned stimulus (US) to establish a CS-US association, and re-exposure to the CS elicits a conditioned fear response. The basolateral amygdalar complex (BLA), which comprises the lateral, basal, and basomedial nuclei, is a key site where the CS-US association occurs (Fendt and Fanselow, 1999; LeDoux, 2000). The associative signal is then relayed to the adjacent central nucleus of the amygdala $(\mathrm{CeA})$, which receives unidirectional projections from the BLA and is hypothesized to act as the final output station of the amygdala (McDonald, 1998; LeDoux, 2000; Pitkänen, 2000). This BLA-to-CeA serial transmission viewpoint is widely supported by studies showing that damage to either the BLA or CeA induces deficits in conditioned fear-related responses (Fanselow and LeDoux, 1999; Maren, 1999; Davis, 2000; Paré et al., 2004; Kim and Jung, 2006).

Recently, the notion of the CeA acting as the primary output structure in fear conditioning has been reconsidered. A study

Received Feb. 12, 2009; revised April 30, 2009; accepted May 2, 2009

This work was supported by National Institutes of Health Grant NS39406. We thank Mark Pilar and Daniel Wilkie for excellent technical assistance.

Correspondence should be addressed to Dr. Lorey K. Takahashi, Department of Psychology, University of Hawaii, 2430 Campus Road, Honolulu, HI 96822. E-mail: LKT@hawaii.edu.

DOI:10.1523/JNEUROSCI.0740-09.2009

Copyright $\odot 2009$ Society for Neuroscience $\quad$ 0270-6474/09/297379-10\$15.00/0 found that fiber-sparing lesions of the CeA failed to impair conditioned freezing in tone-dependent and contextual fear conditioning (Koo et al., 2004). However, robust freezing deficits were reported with either BLA fiber-sparing or CeA electrolytic lesions. Results suggest that disruption of fibers of passage through the $\mathrm{CeA}$ is responsible for deficits in conditioned fear expression (Koo et al., 2004). Moreover, evidence emerged that CeA can mediate memory consolidation. An auditory fear-conditioning study showed that reversible inactivation of the CeA before fear conditioning disrupted fear learning, and protein synthesis inhibition in the CeA impaired the consolidation of fear memory (Wilensky et al., 2006).

Of further relevance to BLA and CeA function, the neuropeptide corticotropin-releasing factor (CRF) influences memory consolidation. Two studies showed that CRF receptor antagonism in the BLA, but not the CeA, impaired inhibitory avoidance (Roozendaal et al., 2002) and contextual fear memory consolidation (Hubbard et al., 2007). However, CRF in the BLA is limited compared with lateral part of the CeA (CeAl), located in the caudal two-thirds of the CeA (Jolkkonen and Pitkänen, 1998), and which contains high densities of CRF immunoreactive cells and fibers (Veening et al., 1984; Sakanaka et al., 1986; Cassell and Gray 1989). Furthermore, exposure to stress elevates extracellular amygdalar CRF fourfold above baseline levels (Cook, 2004), which may reflect CeA CRF secretion (Merlo Pich et al., 1995; Merali et al., 1998). Thus, CeA CRF may facilitate BLA CRF ${ }_{1}$ receptor activation in emotional memory consolidation. However, the function of 
endogenous CeA CRF in fear conditioning remains to be examined.

Therefore, we investigated CeA CRF in contextual fear conditioning using fiber-sparing lesions, temporary inactivation, and CRF specific antisense oligonucleotides (CRF ASO). Using identical training and testing procedures, the lesion and temporary neural inactivation experiments provide a comparative basis to assess the specific effects of CeA CRF. Of further importance, the antisense studies offer novel information on the function of endogenous CeA CRF in contextual fear conditioning.

\section{Materials and Methods}

Animals. Adult male Long-Evans rats (275-325 g) were bred at the University of Hawaii Animal Facility from stock obtained from Charles River Laboratories. Rats were singly housed in polycarbonate cages and maintained on a $12 \mathrm{~h}$ light/dark cycle with lights on at 6:00 A.M. Each cage was provisioned with food and water ad libitum. All procedures were approved by the University of Hawaii Institutional Animal Care and Use Committee and in compliance with the National Institute of Health Guide for the Care and Use of Animals. Every effort was made to minimize animal use and discomfort.

Stereotaxic surgery. Rats were anesthetized with an intraperitoneal injection of ketamine hydrochloride $(100 \mathrm{mg} / \mathrm{kg})$ and xylazine $(20$ $\mathrm{mg} / \mathrm{kg}$ ). Stainless steel 26-gauge guide cannulae (Plastics One) were implanted bilaterally into either the CeA or the BLA using the following flat-skull coordinates: CeA: $-2.0 \mathrm{~mm}$ anteroposterior (AP) from bregma, $\pm 4.2 \mathrm{~mm}$ mediolateral (ML), $-7.0 \mathrm{~mm}$ dorsoventral (DV) from skull; BLA: $-2.2 \mathrm{~mm}$ AP from bregma, $\pm 5.1 \mathrm{~mm} \mathrm{ML},-8.0 \mathrm{~mm}$ DV from skull. Dummy stylets were inserted into guide cannulae and rats were allowed a $10-12 \mathrm{~d}$ postrecovery period. During the recovery period, rats were handled $3-4 \mathrm{~d}$ before testing to adapt to the microinjection procedure.

Microinjections. After removal of dummy stylets, 33-gauge stainless steel cannula injectors extending $1 \mathrm{~mm}$ beyond the guide cannula tip were inserted into the brain. Polyethylene tubing connected each cannula injector to a $10 \mu \mathrm{l}$ syringe that was driven simultaneously at a rate of 0.1 $\mu \mathrm{l} / \mathrm{min}$ by an infusion pump. Injectors remained in place for an additional 3 min to confine the drug to the target site.

Drug preparation. Ibotenic acid (Sigma-Aldrich) was dissolved (10 $\mu \mathrm{g} / \mu \mathrm{l}$ ) in 0.1 M PBS, pH 7.4. Muscimol (Bachem) was dissolved in sterile saline $(0.5 \mu \mathrm{g} / \mu \mathrm{l})$. The CRF specific antisense oligonucleotides (CRF ASO), CRF random sequence oligonucleotides (CRF RSO), and FITClabeled RSO were commercially obtained (Biognostik) and dissolved (2.5 $\mathrm{nmol} / 1.0 \mu \mathrm{l}$ ) in PBS. Oligonucleotides were PAGE-purified phosphorothioate end-capped sequences of 17-18 bps: CRF ASO: $5^{\prime}$-CAA GCG CAA CAT TTC AT-3' (complementary to base pairs 736-752 of the rat CRF mRNA transcript). CRF RSO: 5' -GTA GTC TAG TGT AGT AGT-3' (Biognostik). To further confirm the specificity of the CRF ASO, a BLAST search using the complementary sequence against the rat genome database was performed (Altschul et al., 1990). When the E-value was set at 10 , the only match was the CRF gene. Using identical parameters, a BLAST search for the complementary sequence of the CRF RSO found no matches.

Fear-conditioning apparatus. The apparatus $(25.3 \times 20.3 \times 22.6 \mathrm{~cm})$ was constructed of three white Plexiglas sides and top and a clear front wall for video recording. Scrambled electric footshock (San Diego Instruments) was delivered via the stainless grid floor. The room was illuminated using fluorescent overhead lighting. During testing, a video camera and VCR recorded the behavior of the rat.

Contextual fear-conditioning procedure. For the acquisition of contextual fear, rats were placed in the conditioning apparatus for a $12 \mathrm{~min}$ conditioning trial. After a 2 min pretest interval, five electric foot shocks ( $1 \mathrm{~mA}, 1 \mathrm{~s}$ duration) were delivered at $2 \mathrm{~min}$ intervals. Freezing, defined as the cessation of all body movements except those required for respiration, was videotaped and measured during each 2 min postshock interval. At the conclusion of each test, rats were returned to their home cage. Increased increments in postshock freezing in the shock box likely reflect the acquisition of a conditioned, not unconditioned, fear response, because rats removed from the shock box and placed immediately in a different context show significantly reduced levels of freezing (Blanchard and Blanchard, 1969; Fanselow, 1980). To determine the retention of conditioned fear, rats were returned to the shock box $48 \mathrm{~h}$ after training and contextual fear was assessed for $10 \mathrm{~min}$ in the absence of shock. Behavior was again videotaped and contextual freezing scored by an observer unaware of the treatment condition. At the conclusion of each test, the apparatus was cleaned with $5 \%$ ethanol.

Histology and immunohistochemistry. At the completion of behavioral testing, rats were overdosed with sodium pentobarbital and transcardially perfused with ice-cold PBS, pH 7.4, followed by $0.1 \mathrm{M}$ phosphate buffer, $\mathrm{pH} 7.4$, containing $4 \%$ paraformaldehyde, $\mathrm{pH}$ 7.4. The brains were postfixed for $48 \mathrm{~h}$ in the same fixative (4\% PFA) and then immersed daily in 0, 20, and 30\% sucrose in PBS. Brains were cut into $40 \mu \mathrm{m}$ sections on a cryostat and either mounted onto precleaned Superfrost Plus slides and stained with thionin or stored as free-floating sections in a cryoprotective solution (0.05 M PBS, 25\% glycerol, $25 \%$ polyethylene glycol) at $4^{\circ} \mathrm{C}$. Free-floating sections were stained for either myelin (fibers of passage), NeuN (neuronal nuclei), or CRF. For myelin staining, free-floating sections were transferred to TBS-containing wells and rinsed for $20 \mathrm{~min}$. The tri-color BrainStain Kit (Invitrogen) was prepared immediately before staining by diluting each stock solution 300-fold in PBS within a single container. Tissue sections were immersed in $500 \mu \mathrm{l}$ of staining solution and incubated for $20 \mathrm{~min}$ at room temperature. Sections were rinsed in TBS, mounted on Superfrost slides, and air dried before coverslipping with Vectashield mounting medium (Vector Laboratories). NeuN and CRF immunostaining were performed using the free-floating method with mouse monoclonal anti-NeuN antibody (1:200 dilution; Millipore Bioscience Research Reagents) or rabbit anti-CRF antibody (1:10,000 dilution; Peninsula Labs), followed by biotinylated secondary antibody and avidin-biotin complex system (Vector ABC kit, Vector Laboratories). Diaminobenzidine tetrahydrochloride (DAB; DAB Peroxidase Substrate Kit, Vector Laboratories) was used as a chromogen. Sections were mounted on slides, dehydrated, cleared, and coverslipped.

Lesion assessment. All stained sections were viewed with a Zeiss Axioimager light microscope (Carl Zeiss Microimaging). The location of lesions was determined by examining both thionin-stained and NeuNstained sections with the aid of a rat brain atlas (Paxinos and Watson, 1998).

CeA CRF immunoreactivity density measurements. The density of CeA CRF-ir in cell bodies, fibers, and terminals was quantified in three coronal brain sections: $-2.56,-2.80,-3.14 \mathrm{~mm}$ from bregma (Paxinos and Watson, 1998). These sections were selected for their high content of CRF-ir in the CeAl. All microphotographs were taken at $5 \times$ magnification under identical light intensity and exposure times. Black and white images were imported into ImageJ $1.36 \mathrm{~b}$ and inverted to simulate dark-field illumination. For each image, two area contours were drawn corresponding to the CeA and the BLA. The CeA contour was selected for positive CRF-ir and the adjacent BLA contour acted as a control area. Mean optical density numbers were derived by subtracting the BLA control area from the CeA CRF-ir area. In each brain, the optical density measurements taken from the three coronal sections were summed to obtain a total density score of CeA CRF-ir. The total CeA CRF-ir values were normalized by dividing the numerical score of each CeA microinjected with CRF ASO by the score from the contralateral control CeA microinjected with PBS or CRF RSO. Measuring CRF protein density in identified coronal sections provides simultaneous and precise evaluation of the accuracy of cannula placements in CRF-containing target nuclei and the effectiveness of inhibiting CRF with the CRF ASO.

Experiment 1: pretraining CeA neurotoxic lesions on acquisition and retention of contextual fear. To evaluate the effects of CeA neurotoxic lesions using our contextual fear-conditioning procedures, CeAcannulated rats were anesthetized and microinjected bilaterally with 0.2 $\mu \mathrm{l} /$ side of PBS or ibotenic acid $(10 \mu \mathrm{g} / \mu \mathrm{l})$. After $48 \mathrm{~h}$, rats were placed in the fear-conditioning apparatus and exposed to contextual fear acquisi- 
A

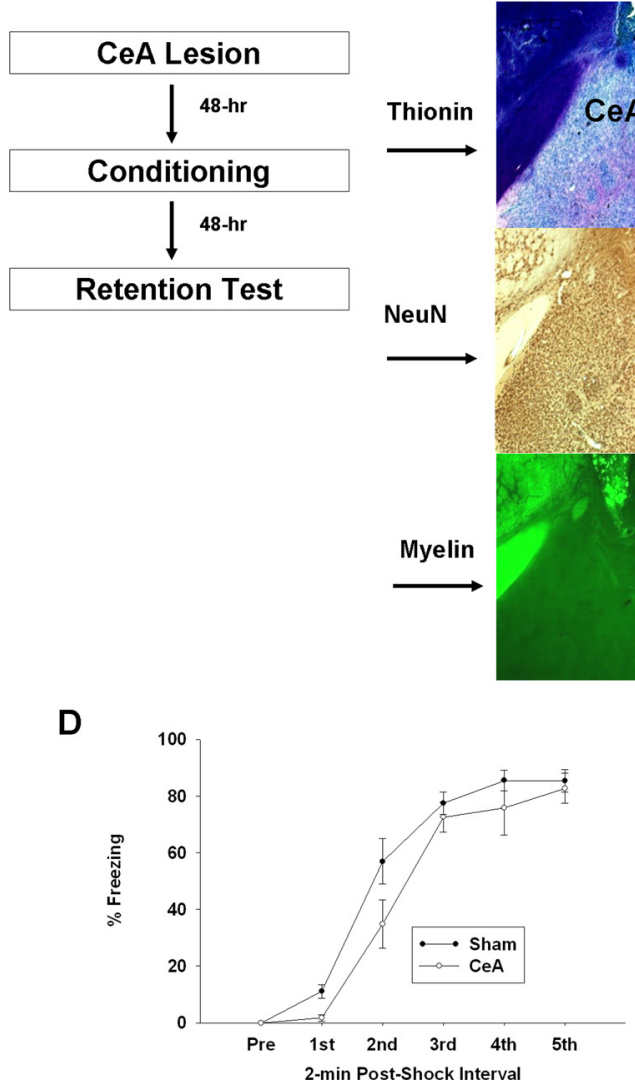

B

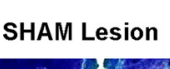

C
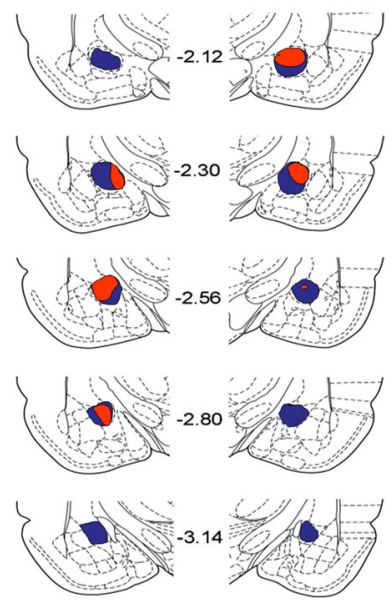

Blue $=$ Largest Lesion

Red $=$ Smallest Lesion

E

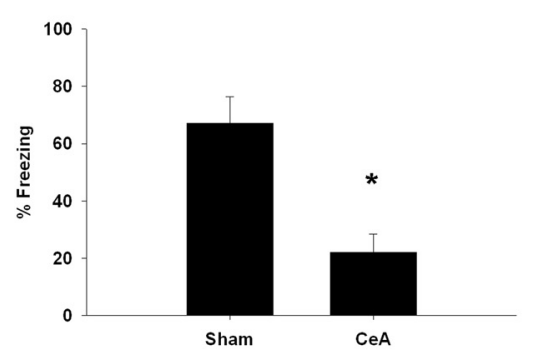

Figure 1. Effects of pretraining fiber-sparing lesions of the central nucleus of the amygdala on acquisition and retention of contextual freezing. $A$, Contextual fear-conditioning testing procedure. $B$, Photomicrographs (magnification $5 \times$ ) of thionin-stained (top), NeuN-immunopositive (middle), and FluoroMyelin Green fluorescent myelin-stained (bottom) from control- (left panels), and ibotenic acid (eA-lesioned (right panels) brains. Note the gliosis in thionin-stained (top right) and neuron loss as revealed by NeuN staining (middle right) at the CeA lesion site. However, fibers of passage in the CeA were intact as shown by myelin staining in both control and lesioned brains. C, Schematic representations of largest (red areas) and smallest (blue areas) ibotenic acid-induced lesions in rostral to caudal CeA coronal levels [numbers indicate millimeters posterior from bregma, Paxinos and Watson (1998)]. D. Mean ( \pm SE) percentage of contextual freezing before and after each 2 min postshock acquisition trial. $E$, Mean ( + SE) percentage of contextual freezing in the 10 min retention test. ${ }^{*}$ significantly different from sham group, $p<0.001$ ( $n=8$ per group).

tion as described in the contextual fear-conditioning procedure section (see also Fig. 1A). At the conclusion of behavioral testing, rat brains were prepared for staining with thionin and NeuN to determine the location of the lesion, and myelin to verify intact fibers of passage at the lesion site.

Experiment 2: effects of temporary inactivation of the CeA before contextual fear conditioning. To assess the effects of reversible inactivation of the CeA using our contextual fear-conditioning procedure, CeA-cannulated rats were microinjected bilaterally with saline or muscimol (100 ng/0.2 $\mu \mathrm{l} /$ side). After $15 \mathrm{~min}$, rats were exposed to contextual fear acquisition and retention as described in the contextual fear-conditioning procedure section (see also Fig. 2A). At the conclusion of testing, brains were prepared for histological verification of cannula tip in the CeA.

Experiment 3: effects of acute inactivation of the CeA before contextual fear retention testing. This study determined whether inactivation of the CeA during retention testing impairs contextual freezing. The fearconditioning test procedure was identical to experiment 2 , except that rats received either saline $(0.2 \mu \mathrm{l} /$ side) or muscimol (100 ng in $0.2 \mu \mathrm{l} /$ side) microinjections $15 \mathrm{~min}$ before the retention test.

Experiment 4: effects of microinjection of CRF ASO in the CeA on CRF immunoreactivity density. Before determining the behavioral effects of CRF ASO on contextual fear conditioning, CeA-cannulated rats were microinjected with FITC-labeled oligonucleotides at volumes and doses estimated to be effective in behavioral studies (Malkani et al., 2004; Lee et al., 2005; McIntyre et al., 2005). After identifying an appropriate microinjection volume $(0.4 \mu \mathrm{l})$ and dosage $(1 \mathrm{nmol})$ (Fig. $3 B)$, we then assessed the effects of the CRF ASO on the density CRF-ir. Cannulated rats were microinjected with CRF ASO into the left or right CeA, and PBS or the
CRF RSO was administered in the contralateral CeA. At 5 and $48 \mathrm{~h}$ after microinjection, rat brains were prepared for determining the optical density of CeA CRF-ir.

Experiment 5: effects of pretraining microinjection of a CRF ASO into the $C e A$ on acquisition and retention of contextual fear. To evaluate the effects of the CRF ASO in the CRF-rich CeA on contextual fear conditioning, CeA-cannulated rats were microinjected bilaterally $(0.4 \mu \mathrm{l} /$ side $)$ with PBS, CRF RSO ( $1 \mathrm{nmol})$, or CRF ASO ( $1 \mathrm{nmol})$. Five hours after microinjection, rats were exposed to the contextual fear acquisition test and returned to their home cage (Fig. $4 A$ ). After $48 \mathrm{~h}$, rats were returned to the shock box for the contextual retention test.

Experiment 6: effects of pretraining microinjection of a CRF ASO into the $B L A$ on acquisition and retention of contextual fear. In this study, the CRF ASO was administered into the BLA to assess the neuroanatomical specificity of the CRF ASO in contextual fear conditioning. The testing procedure was identical to experiment 5 except that rats were microinjected bilaterally $(0.4 \mu \mathrm{l} /$ side) with PBS, CRF RSO $(1 \mathrm{nmol})$, or CRF ASO (1 $\mathrm{nmol}$ ) into the BLA.

Experiment 7: effects of microinjection of a CRF ASO into the CeA before contextual fear retention testing. This study determined whether microinjection of the CRF ASO into the CeA $5 \mathrm{~h}$ before retention testing impairs contextual freezing. All CeA-cannulated rats were first exposed to the contextual fear acquisition procedure and then returned to their home cage. After $48 \mathrm{~h}$, rats were microinjected $(0.4 \mu \mathrm{l} / \mathrm{side})$ bilaterally with either PBS or CRF ASO ( $1 \mathrm{nmol})$ and tested $5 \mathrm{~h}$ later in the retention test.

Data analysis. Behavioral data were evaluated with ANOVA. Specifically, acquisition of contextual freezing was analyzed using repeated 
A

\begin{tabular}{|c|}
\hline Muscimol Infusion \\
\hline$\downarrow^{15-m i n}$ \\
\hline Conditioning \\
\hline$\downarrow^{48-h r}$ \\
\hline Retention Test \\
\hline
\end{tabular}

B
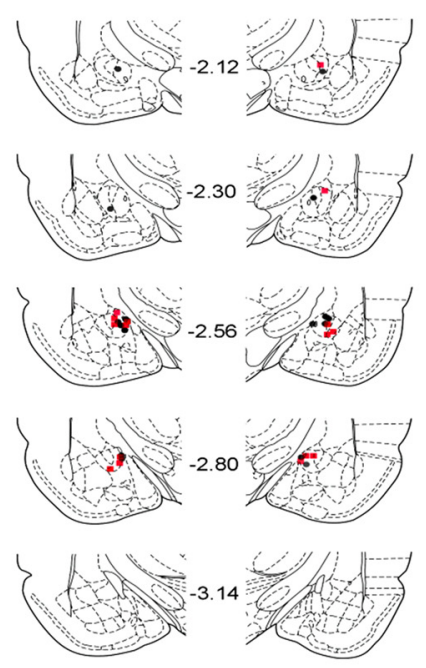

- Saline

Muscimol
C

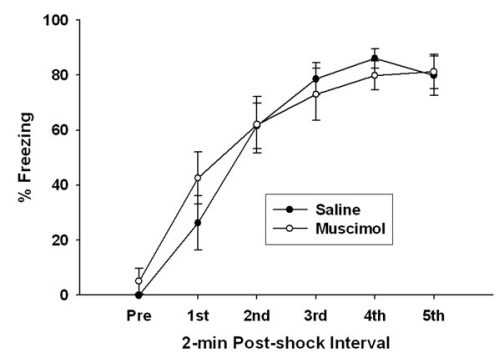

D

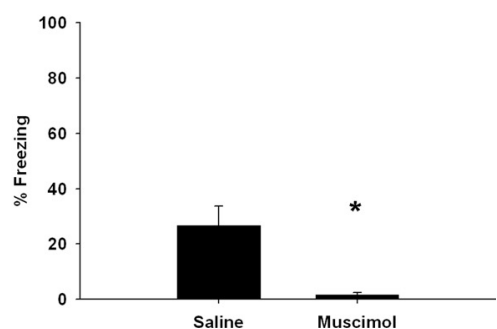

Figure 2. Effects of pretraining reversible inactivation of the central nucleus of the amygdala on acquisition and retention of contextual freezing. $\boldsymbol{A}$, Contextual fear-conditioning testing procedure. $\boldsymbol{B}$, Location of bilateral cannula tip placements in the CeA. The midline numbers refer to the coronal posterior distance in millimeters from bregma (adapted from Paxinos and Watson, 1998). C, Mean ( \pm SE) percentage of contextual freezing before and after each 2 min postshock acquisition trial. $\boldsymbol{D}$, Mean (+SE) percentage of contextual freezing in the 10 min retention test. ${ }^{*}$ significantly different from sham group, $p<0.01$ ( $n=8$ per group).

measures ANOVA (e.g., drug $\times$ postshock interval). Contextual freezing data obtained in the retention test was analyzed with one-way ANOVA or $t$ tests. Post hoc analysis after a significant ANOVA was performed using Scheffe's test. To assess the effects of CRF ASO on total CeA CRF-ir density, paired $t$ tests were used to compare optical density measurements between CRF ASO and the contralateral PBS or RSO sections.

\section{Results}

Experiment 1: pretraining fiber-sparing lesions of the $\mathrm{CeA}$ impairs retention but not acquisition of contextual freezing

To evaluate the general effects of fibersparing lesions using our contextual fearconditioning test procedure, rats received ibotenic acid or sham lesions in the CeA $48 \mathrm{~h}$ before exposure to contextual fear conditioning followed by retention testing $48 \mathrm{~h}$ later (Fig. 1A). The lesions (Fig. $1 B, C$ ) were restricted to the CeA and damage to $\mathrm{CeAl}$ was found in coronal levels -2.12 to -3.14 (Jolkkonen and Pitkänen, 1998; Paxinos and Watson, 1998). The capsular, intermediate, and medial divisions of the CeA were also completely destroyed or damaged throughout these coronal levels.

During acquisition, both CeA-lesion and CeA-sham rats showed little or no freezing during the initial 2 min preshock interval. However, after delivery of footshock, both groups showed significant increases in contextual freezing $\left(F_{(5,70)}=131.72, p<0.001\right)$ (Fig. $\left.1 D\right)$. Contextual freezing increased reliably in postshock intervals $1-3$

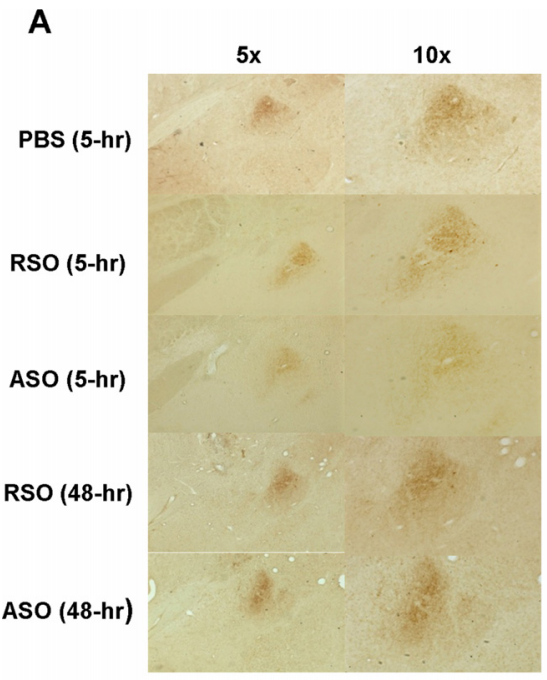

B

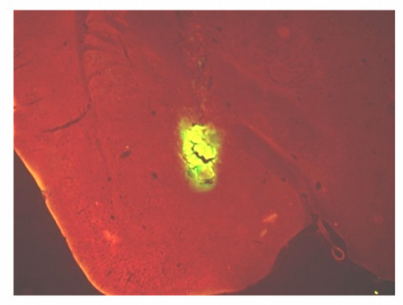

C

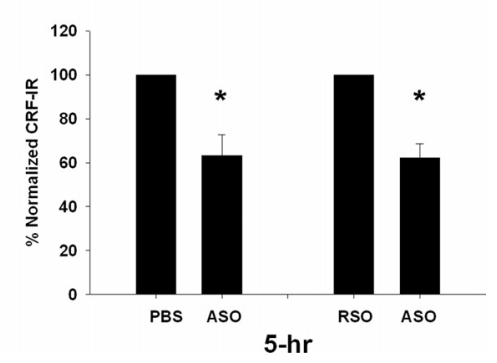

Figure 3. Optical density levels of CRF immunoreactivity in the central nucleus of the amygdala after CRF antisense oligonucleotide administration. $A$, Representative photomicrographs showing CeA CRF-ir occurring $5 \mathrm{~h}$ after microinjection into the CeA with PBS, $1 \mathrm{nmol}$ of CRF RSO, or $1 \mathrm{nmol}$ of CRF ASO and $48 \mathrm{~h}$ after microinjection with CRF RSO and CRF ASO. Note the reduction in CRF-ir $5 \mathrm{~h}$, but not $48 \mathrm{~h}$, after microinjection of CRF ASO into the CeA. No gross necrosis, vacuolation, or other visible neuronal loss was present in the CeA or adjacent areas. Magnification: $5 \times$, left panels; $10 \times$, right panels. $\boldsymbol{B}$, Diffusion of FITC-labeled CRF RSO $(1 \mathrm{nmol} / 0.4 \mu \mathrm{l})$ microinjected into the $C \mathrm{eA}$ is shown in a coronal section at $2.5 \times$ magnification. The placement of the cannula track is visible as glial scar tracts. C, Effect of microinjections of CRF ASO (1 nmol) relative to PBS and CRF RSO (1 nmol) control groups on CeA CRF-ir optical density levels. Optical density measurements were normalized to obtain percentage of CRF-ir density levels. CRF ASO group significantly different from contralateral PBS or CRF RSO group, ${ }^{*} p<0.05$.

and remained at high levels in postshock intervals 3-5. No significant differences in the acquisition of contextual freezing were found between CeA-lesion and CeA-sham groups $\left(F_{(1,14)}=2.28\right.$, $p>0.05)$. The group $\times$ postshock interval interaction was also 
A

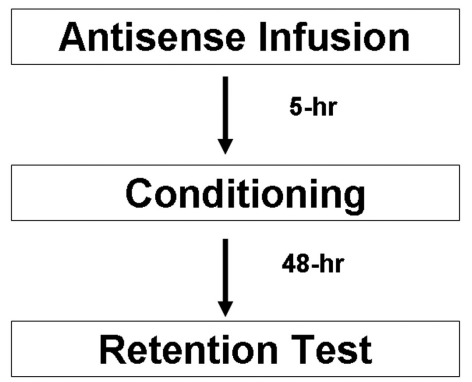

B

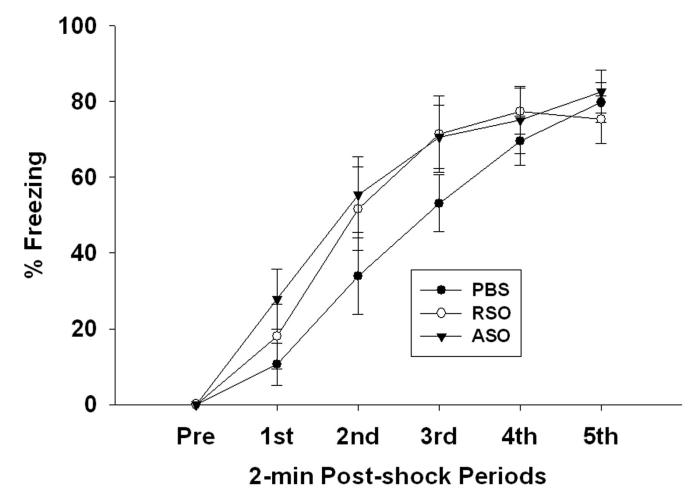

C

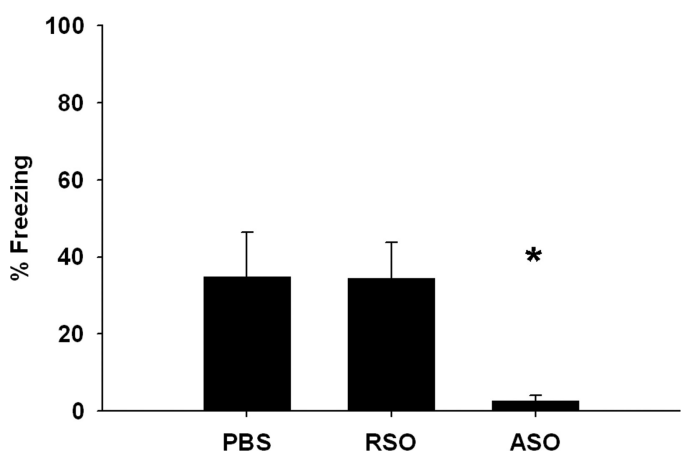

Figure 4. Effects of pretraining reduction in CRF immunoreactivity in the central nucleus of amygdala on acquisition and retention of contextual freezing. $A$, Contextual fear-conditioning testing procedure. $\boldsymbol{B}$, Mean $( \pm \mathrm{SE})$ percentage of contextual freezing before and after each 2 min postshock acquisition trial. $C$, Mean ( + SE) percentage of contextual freezing in the $10 \mathrm{~min}$ retention test. ${ }^{*}$ significantly different from PBS and CRF ASO groups, $p<0.01$. (PBS: $n=6$; $\mathrm{RSO}: n=8 \mathrm{ASO}: n=8$ ).

not significant $\left(F_{(5,70)}=1.42, p>0.05\right)$. When tested after $48 \mathrm{~h}$ in the retention test, CeA-lesion rats exhibited significantly lower levels of contextual freezing than CeA-sham rats $\left(t_{14}=4.73, p<\right.$ 0.001 ) (Fig. $1 E$ ). These results suggest that the CeA contributes to retention, but not acquisition, of contextual fear.

We found that four additional rats had misplaced fibersparing lesions that destroyed neurons in the BLA. In three rats, unilateral BLA lesions were accompanied by contralateral CeA lesions, and one rat received bilateral BLA lesions. These four rats exhibited pronounced contextual freezing deficits in each of the five successive postshock acquisition intervals (mean percentage freezing $=0.0,0.3,6.7,29.2,45.7$ ) and in the retention test (mean percentage freezing $=3.6$ ). On the basis of this small sample size, results appear consistent with previous studies showing that an intact BLA is essential in the acquisition of contextual fear conditioning (Koo et al., 2004).

Experiment 2: pretraining reversible inactivation of the CeA impairs retention but not acquisition of contextual freezing To extend our experiment 1 results, the CeA was temporarily inactivated with the GABA agonist muscimol during exposure to contextual fear conditioning (Fig. $2 A, B$ ). Rats treated with vehicle or muscimol $15 \mathrm{~min}$ before training exhibited no significant contextual freezing differences in the acquisition test $\left(F_{(1,14)}=\right.$ 0.06, $p>0.05$ ) (Fig. 2C). The duration of contextual freezing increased significantly across the postshock acquisition intervals $\left(F_{(5,70)}=70.39, p<0.001\right)$ and the drug $\times$ postshock interval interaction was not significant $\left(F_{(5,70)}=1.19, p>0.05\right)$. In the drug-free contextual retention test, muscimol-treated rats displayed significantly less freezing than vehicle-treated animals $\left(t_{14}\right.$ $=3.50, p<0.01$ ) (Fig. 2D). These results are consistent with those in experiment 1 by demonstrating that temporary inactivation of the CeA has no significant effects on the acquisition of contextual freezing. In addition, this reversible inactivation study extends the results of experiment 1 by showing that freezing deficits in retention testing are not caused by impairment in CeA function.

\section{Experiment 3: CeA inactivation does not impair contextual} freezing expression in the retention test

To further evaluate whether the CeA plays a modulatory role in memory retention, rats were microinjected with vehicle or muscimol into the CeA 15 min before the contextual fear retention test. No significant differences in contextual freezing $\left(t_{13}=0.07\right.$, $p>0.05$ ) were found between vehicle (mean percentage \pm SEM, $50.5 \pm 12.1 ; n=7)$ and muscimol-treated rats (49.5 $\pm 9.2 ; n=$ $8)$. These results, in conjunction with those obtained in the previous two experiments, suggest the CeA does not participate in contextual fear expression but plays an important role in the consolidation of contextual fear memory. Although experiments 2 and 3 did not measure the spread of muscimol diffusion from the CeA, the actions of muscimol likely did not extend into the adjacent BLA because contextual freezing was not impaired in either the acquisition or retention test.

\section{Experiment 4: microinjection of CRF ASO into the CeA} reduces CRF-ir after $5 \mathrm{~h}$ but not $48 \mathrm{~h}$

To determine whether CeA CRF is critically involved in contextual fear conditioning, we obtained ASO to specifically inhibit production of CRF peptide. We first evaluated the attenuating effects of CRF ASO on CeA CRF-ir. Microinjections of CRF ASO ( $1 \mathrm{nmol}$ in a volume of $0.4 \mu \mathrm{l}$ ) into the CeA induced a significant reduction $5 \mathrm{~h}$ later in optical density of CeA CRF-ir compared with CRF-ir levels in the contralateral CeA treated with PBS $\left(t_{4}=\right.$ 3.91, $p<0.05)$ or CRF RSO $\left(t_{5}=5.96, p<0.01\right)$ (Fig. $3 A, C$ ). Further analysis revealed that $48 \mathrm{~h}$ after CRF ASO administration, CeA CRF-ir levels were not significantly different between CRF RSO and CRF ASO groups $\left(t_{3}=0.13, p>0.05\right)$ (Fig. $3 A$, RSO $48 \mathrm{~h}$ and ASO $48 \mathrm{~h}$ photomicrographs). Although the CRF ASO infusion volume $(0.4 \mu \mathrm{l})$ was higher than injection volumes used in our muscimol studies $(0.2 \mu \mathrm{l})$, ASO diffusion was confined to the CeA (Fig. 3B), possibly because of the high molecular weight of oligonucleotides (muscimol $=114.1,18$-mer oligo $\sim 5500$ ). 
A
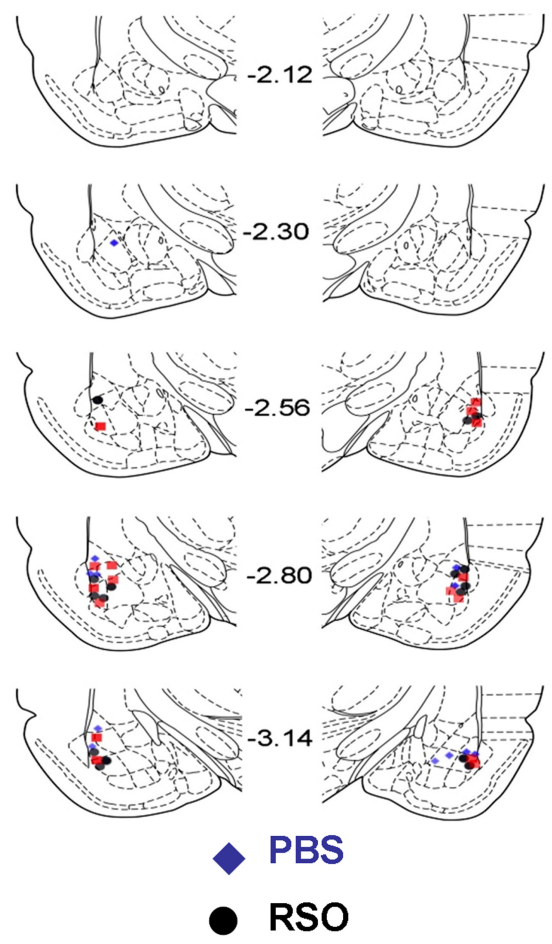

ASO
B

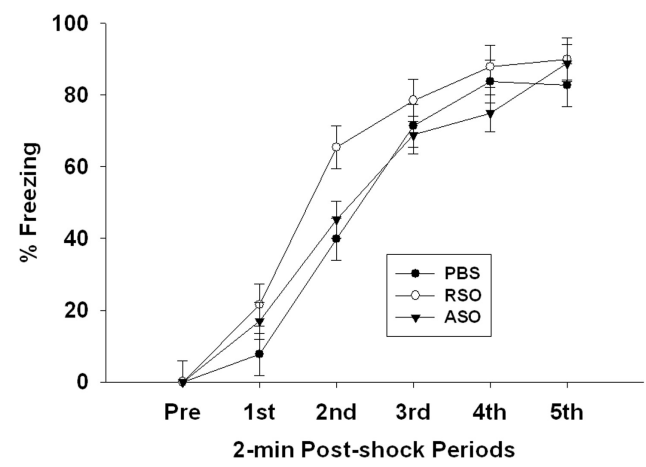

C

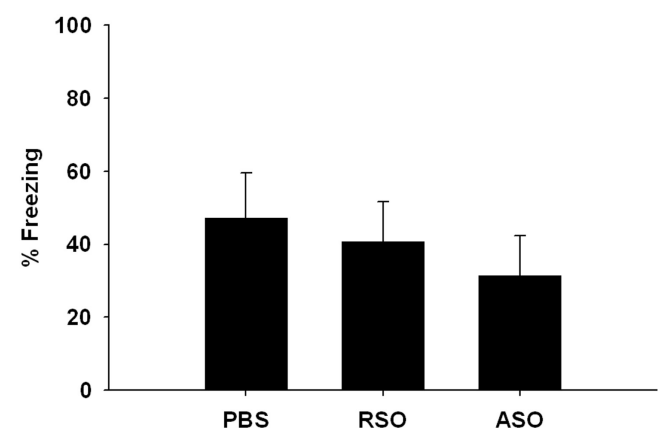

Figure 5. Effects of pretraining microinjection of CRF antisense oligonucleotide in the basolateral amygdala on acquisition and retention of contextual freezing. $\boldsymbol{A}$, Location of bilateral cannula tip placements in the BLA. The midline numbers refer to the coronal posterior distance in millimeters from bregma (adapted from Paxinos and Watson, 1998). $\boldsymbol{B}$, Mean ( \pm SE) percentage of contextual freezing before and after each 2 min postshock acquisition trial. $C$, Mean ( $+S E)$ percentage of contextual freezing in the 10 min retention test (PBS: $n=6 ; \mathrm{RSO}$ : $n=8 ;$ ASO: $n=8$ )

\section{Experiment 5: pretraining microinjection of a CRF ASO into the $\mathrm{CeA}$ impairs retention but not acquisition of contextual fear}

The results of experiments 1 and 2 showed that general disruption of the CeA occurring before contextual fear training using either fiber-sparing lesion or reversible inactivation methods significantly impaired the retention but not the acquisition of contextual freezing. To further extend these results, we determined whether CRF in the CeA is critically involved in contextual fear conditioning by inhibiting CeA CRF with an ASO. Cannulated rats were microinjected with $\mathrm{PBS}$, RSO, or CRF ASO into the CeA and exposed to contextual fear conditioning $5 \mathrm{~h}$ later when CeA CRF-ir is reduced, as shown in experiment 4. Forty-eight hours after conditioning, when CeA CRF-ir returns to control levels, rats were tested for contextual fear retention (Fig. 4A). In this study, the majority of CeA cannula tips were located in coronal sections $-2.56(54.5 \%)$ and $-2.8(25 \%)$ (see Fig. $2 B$ for identification of CeA coronal levels). A small number of CeA cannula tips were also found in coronal sections $-2.3(9.1 \%)$ and -3.14 $(11.4 \%)$.

A repeated measures ANOVA showed no significant main effect of drug $\left(F_{(2,19)}=0.85, p>0.05\right)$ or drug $\times$ postshock interval interaction $\left(F_{(10,95)}=1.00, p>0.05\right)$ on acquisition of contextual freezing (Fig. $4 B$ ). However, the main effect of the postshock interval was highly significant $\left(F_{(5,95)}=102.22\right.$, $p<0.001)$. Contextual freezing increased significantly across the postshock trials $1-3$ and remained elevated from trials 3-5.
In the retention test, a one-way ANOVA revealed significant group differences in contextual freezing $\left(F_{(2,19)}=5.55, p<\right.$ 0.05 ) (Fig. $5 C$ ). Rats previously microinjected with CRF ASO into the CeA showed a significant reduction on contextual freezing compared with PBS and CRF RSO groups $(p<0.01)$. These results implicate CeA CRF activity in contextual fear conditioning.

It should be noted that an early study using an ASO against CRF required multiple injections into the hippocampus to produce a significant reduction on CRF mRNA and inhibitory avoidance memory retention (Wu et al., 1997). In contrast, we required only one CRF ASO injection into the CeA to produce a significant reduction $5 \mathrm{~h}$ later in CRF-ir and deficits in contextual fear retention. Our CRF ASO has a different oligonucleotide sequence of 17-18 bps, which appears to have increased efficacy in inhibiting CRF in the CeA. As indicated previously, a number of recent studies reported using highly efficient ASO to inhibit the target protein within a few hours after one injection into brain tissue with resultant deficits in behavior (Malkani et al., 2004; Lee et al., 2005; McIntyre et al., 2005).

The extent to which our CRF ASO microinjected into the CeA $5 \mathrm{~h}$ before training significantly inhibits not only CRF synthesis but also reduces previously stored CRF in release sites remains to be determined. However, a potential inability of CRF ASO to attenuate secretion of previously synthesized CRF does not necessary indicate that activation of $\mathrm{CeA} \mathrm{CRF}{ }_{1}$ receptors is required in facilitating the acquisition of contextual freezing. That is, the 
postshock increase in freezing expression may not require CeA $\mathrm{CRF}_{1}$ receptors, because, as previously demonstrated, antagonism of CeA CRF $F_{1}$ receptors does not impair the immediate postshock freezing performance of rats in contextual training (Hubbard et al. 2007). Our CRF ASO may be inhibiting CRF mRNA and newly synthesized CRF for release over a critical time-limited posttraining period in the CeA to compromise the consolidation of contextual fear memory.

\section{Experiment 6: pretraining microinjection of a CRF ASO into the BLA does not impair acquisition and retention of contextual fear}

To further determine the neuroanatomical and behavioral specificity of the CRF CeA inhibition, we microinjected PBS, RSO, or CRF ASO into the BLA (Fig. 5A) $5 \mathrm{~h}$ before contextual fear conditioning, using identical testing procedures as in experiment 5 (Fig. 4A). During contextual fear acquisition (Fig. 5B), we found no significant effects of drug $\left(F_{(2,19)}=0.533, p>0.05\right)$ and drug $\times$ postshock interval interaction $\left(F_{(10,95)}=0.81, p>0.05\right)$. However, contextual freezing increased significantly across the postshock intervals $\left(F_{(5,95)}=125.78, p<0.001\right)$. When returned to the test environment $48 \mathrm{~h}$ later, freezing levels did not differ significantly across treatment groups $\left(F_{(2,19)}=0.474, p>0.05\right)$ (Fig. $5 C$ ). The results of this study suggest that stimulation of CeA $\mathrm{CRF}$, and not BLA CRF, is critically involved in facilitating contextual fear conditioning. In addition, the failure to induced deficits in contextual freezing suggests the CRF ASO does not produce general unwanted toxic effects on brain cells.

\section{Experiment 7: CeA CRF does not impair contextual freezing expression in the retention test}

Experiment 3 showed that pharmacological inactivation of the CeA did not impair the expression of contextual fear. This study extends the previous work by determining whether specific ASO inhibition of CeA CRF influences contextual fear expression. CeA-cannulated animals were initially exposed to contextual fear conditioning. Two days later, rats were microinjected with PBS or CRF ASO (see Fig. $2 B$ for similar cannula tip placements) $5 \mathrm{~h}$ before contextual fear retention testing, a postinjection period when CeA CRF-ir levels were shown to be reduced (Fig. 3A). Results indicated no significant deficits in contextual freezing $\left(t_{11}\right.$ $=0.46, p>0.05$ ) between PBS (mean percentage \pm SEM; $29.5 \pm$ $4.8 ; n=6)$ and CRF ASO injected groups (36.0 $\pm 12.3 ; n=7)$.

These results demonstrate that CeA CRF is not a major participant in contextual fear expression. The results of experiments 5,6 , and 7 also suggest that CRF ASO administration into the CeA or BLA does not produce nonspecific behavioral effects (e.g., hyperlocomotion). Finally, experiments 2, 3, 5, and 7 showed that muscimol or CRF ASO administration into the CeA has no significant effects on the occurrence of freezing in the immediate acquisition or retention test.

\section{Discussion}

We report that pretraining fiber-sparing lesion and reversible inactivation of the CeA induced freezing deficits only in the retention and not in the acquisition test. Importantly, using identical testing methods, we demonstrated that pretraining CRF ASO administration into the CeA similarly impaired the retention but not acquisition of contextual freezing. Although the lesion and reversible inactivation methods do not specifically target CeA CRF functions, their general disrupting effects likely attenuated the fear conditioning induced activation of CeA CRF secretion, which compromised fear memory consolidation.
Our results are consistent, in part, with another study that questioned the necessity of CeA activity for fear expression (Koo et al., 2004). In both studies, pretraining CeA fiber-sparing lesions failed to disrupt the acquisition of contextual freezing. The previous report also showed that CeA electrolytic lesions, which destroy neurons and fibers of passage, impaired both the acquisition and retention of contextual fear. The authors suggested the BLA serves to establish the CS-US association, and fear expression is dependent on BLA projections traversing through the CeA to the bed nucleus of the stria terminalis (BST) (Dong et al., 2001; Koo et al., 2004), which projects to the periaqueductal gray (Dong and Swanson, 2004), a site involved in contextual freezing expression (LeDoux et al., 1988; Walker and Carrive, 2003). However, in contrast, we found CeA activity during conditioning to be a prerequisite for the formation of contextual fear memory. Behavioral discrepancies underlying the specific role of the CeA in contextual fear conditioning are not clear, but some procedural differences between studies merit consideration. In their experiments, Sprague Dawley rats received bilateral $0.1 \mu \mathrm{l}$ of ibotenic acid at two CeA sites and were allowed to recover at least $10 \mathrm{~d}$ before fear-conditioning training. Our Long-Evans rats were microinjected with $0.2 \mu$ l of ibotenic acid through indwelling guide cannulae $48 \mathrm{~h}$ before training to minimize potential compensatory rewiring during the postlesion period as suggested by other studies (Wilensky et al., 2006; Zimmerman et al., 2007). In addition, our rats were trained using five footshocks interspersed with 2 min intertrial intervals and tested for retention $48 \mathrm{~h}$ later, whereas in the previous study (Koo et al., 2004) animals were exposed to 10 coterminating tone-footshock pairings with $1 \mathrm{~min}$ intertrial intervals before retention testing $24 \mathrm{~h}$ later. Differences in rat strain, lesion size, location, training protocols, and timing of CeA lesion and testing may contribute to behavioral discrepancies.

Concerning the role of the CeA in memory consolidation, an auditory fear-conditioning study demonstrated that either pretraining inactivation or posttraining protein synthesis inhibition impaired fear retention (Wilensky et al., 2006). Consequently, the authors hypothesized that the CeA, like the BLA, is a site of fear acquisition and memory storage. The CeA was also reported to compensate for the loss of BLA function when BLA lesioned rats are exposed to extensive overtraining (75 CS-US trials) (Zimmerman et al., 2007). However, we found preretention CeA inactivation with muscimol or inhibition with CRF ASO had no impairing effects on contextual freezing, suggesting the CeA is not a general repository of fear memory but a site that modulates the storage of contextual fear memory in other brain regions, which may include an intact BLA (Koo et al., 2004). Underlying differences in the amygdalar neural circuitry that processes toneshock and context-shock associations may account for these behavioral inconsistencies. For example, auditory information specifically enters the lateral nucleus of the amygdala and the medial division of the CeA via the thalamus, whereas contextual information is sent from the hippocampus to the BLA and CeAl (McDonald and Mascagni, 1997; Paré et al., 2004; Maren, 2005).

In contextual fear conditioning, emotional and sensory components of the US may facilitate CeAl CRF secretion by projections originating from the posterior agranular insular cortex (McDonald, 1998), BLA (Pitkänen et al., 1997), external lateral parabrachial nucleus (Jasmin et al., 1997), and hippocampus (McDonald and Mascagni, 1997). Furthermore, studies suggest a critical role of CeA CRF in contextual fear conditioning by showing that corticosterone stimulates amygdalar CRF secretion (Cook, 2002; Merali et al., 2008), increases CeA CRF mRNA 
(Makino et al., 1994; Watts and Sanchez-Watts, 1995), and facilitates contextual fear retention (Thompson et al., 2004). In addition, similar to our CeA CRF ASO study, transgenic mice with conditional knock-out of CeA type II glucocorticoid receptors exhibited typical freezing levels in conditioned fear training, but freezing deficits emerged in the retention test suggesting an impairment in fear memory consolidation (Kolber et al., 2008). This freezing retention deficit was reversed by pretraining intracerebroventricular administration of CRF, which indicates that activation of CeA glucocorticoid receptors influences CeA CRF secretion. Our work extends these CeA studies by showing a novel and important role of CeA CRF activation in facilitating contextual fear memory.

Several possibilities may account for how endogenous CeA CRF secretion facilitates the consolidation of contextual fear memory. One possibility is that $\mathrm{CRF}_{1}$ receptors located in the CeA (Justice et al., 2008; Treweek et al., 2009) may be activated by CeA CRF to consolidate contextual fear memory. However, as previously demonstrated in this laboratory, $\mathrm{CRF}_{1}$ receptor activation in the BLA, and not in the CeA, plays an essential role in contextual fear memory (Hubbard et al., 2007). Furthermore, we showed that ASO-induced inhibition of CRF in the BLA does not significantly impair contextual freezing. This neuroanatomical mismatch between CeA CRF and BLA CRF ${ }_{1}$ receptors in contextual fear conditioning does not rule out a putative CRF circuit underlying contextual fear memory. That is, peptides can be found in brain sites lacking prominent receptor populations (Herkenham, 1987), and neuropeptides released from dendrites distal from receptor dense regions are capable of altering behavior (Ludwig and Leng, 2006). Hence, exposure to contextual fear conditioning may increase endogenous CeA CRF secretion (Cook, 2004) and contribute to the activation of $\mathrm{CRF}_{1}$ receptors located in the adjacent BLA (Chalmers et al., 1995; Radulovic et al., 1998, Van Pett et al., 2000) to modulate the consolidation of contextual fear. Of further potential relevance, transgenic mice with a green fluorescent protein (GFP) reporter for $\mathrm{CRF}_{1}$ receptors were found to have $\mathrm{CRF}_{1}-\mathrm{GFP}$-positive fibers in the intercalated nuclei, located at the border of the CeAl and the BLA (Justice et al., 2008). Moderate $\mathrm{CRF}_{1}$ mRNA expression but very few $\mathrm{CRF}_{1}-\mathrm{GFP}$-positive cell bodies were found within the BLA. These results raise the possibility that $\mathrm{CRF}_{1}$ mRNA is transcribed in BLA neurons and translated in dendrites near the $\mathrm{CeAl}$, thus reducing the distance between presynaptic CeA CRF and postsynaptic BLA $\mathrm{CRF}_{1}$ receptors. Studies will be required to elucidate this complex amygdalar CRF circuit in contextual fear conditioning.

Another possibility is the CRF-binding protein (CRF-BP), found in both membrane-associated and soluble forms and expressed in CeA and BLA (Potter et al., 1992; Herringa et al., 2004), may transport CRF from the CeA to activate BLA CRF $\mathrm{C}_{1}$ receptors. Posttraining microinjections of CRF-BP ligand inhibitor $\mathrm{CRF}_{6-33}$ into the BLA enhanced inhibitory avoidance retention (Roozendaal et al., 2008), and suggest that CRF displacement from the binding protein promotes conditioned fear. However, several studies suggest the function of CRF-BP is to modulate or attenuate CRF receptor activation (Potter et al., 1992; Jahn et al., 2005; Westphal and Seasholtz, 2006). For instance, CRF-BPdeficient mice exhibit an elevation in anxiety-like behavior, which may result from anxiogenic effects of increased "free" CRF (Karolyi et al., 1999). CRF-BP mRNA also increases in the BLA up to $21 \mathrm{~h}$ after exposure to restraint stress, which may buffer an otherwise abnormal stress-induced rise in CRF accompanied by heightened CRF receptor actions (Herringa et al., 2004). Future studies should determine under physiological conditions whether CRF-BP is an important source of endogenous CRF that activates $\mathrm{BLA} \mathrm{CRF}_{1}$ receptors.

The CRF-dense CeAl may also contribute to fear conditioning via major projections to the BST (Petrovich and Swanson, 1997). Studies reported that BST lesions impaired contextual freezing (Sullivan et al. 2004) and fear behavior in a context associated with long duration CSs (Waddell et al., 2006). Our lesion, reversible inactivation, and CRF ASO procedures that targeted the CeA may have disrupted BST functions underlying contextual fear conditioning. Of further interest, potentiated startle appears dependent on contextual cues and CRF receptor subtypes likely located in the amygdala and BST (Risbrough et al., 2009; Walker et al., 2009). In addition, the BST fusiform nucleus, a major CeAl projection site, is an important participant in stress hormone secretion (Choi et al., 2007), and chronic overexpression of CeA CRF was reported to dysregulate the hypothalamic-pituitaryadrenal system (Keen-Rhinehart et al., 2009). Whether our temporary CRF ASO induced inhibition of CeA CRF attenuated glucocorticoid secretion, which may disrupt fear memory consolidation (Roozendaal, 2003), requires further analysis.

Collectively, our results highlight a role of the CeA, and particularly CeA CRF secretion, as a key component in contextual memory consolidation but not fear expression. Therefore, we propose an expanded contextual fear neural circuit model in which the CS-US association is mediated, in part, by fearconditioning stimulation of CeA CRF secretion that may activate $\mathrm{BLA} \mathrm{CRF}_{1}$ receptors and possibly CeAl projection sites to the BST to establish contextual fear memory.

\section{References}

Altschul SF, Gish W, Miller W, Myers EW, Lipman DJ (1990) Basic local alignment search tool. J Mol Biol 215:403-410.

Blanchard RJ, Blanchard DC (1969) Crouching as an index of fear. J Comp Physiol Psychol 67:370-375.

Cassell MD, Gray TS (1989) Morphology of peptide-immunoreactive neurons in the rat central nucleus of the amygdala. J Comp Neurol 281:320-333.

Chalmers DT, Lovenberg TW, De Souza EB (1995) Localization of novel corticotropin-releasing factor receptor $\left(\mathrm{CRF}_{2}\right) \mathrm{mRNA}$ expression to specific subcortical nuclei in rat brain: comparison with $\mathrm{CRF}_{1}$ receptor mRNA expression. J Neurosci 15:6340-6350.

Choi DC, Furay AR, Evanson NK, Ostrander MM, Ulrich-Lai YM, Herman JP (2007) Bed nucleus of the stria terminal subregions differentially regulate hypothalamic-pituitary-adrenal axis activity: implications for the integration of limbic inputs. J Neurosci 27:2025-2034.

Cook CJ (2002) Glucocorticoid feedback increases the sensitivity of the limbic system to stress. Physiol Behav 75:455-464.

Cook CJ (2004) Stress induces CRF release in the paraventricular nucleus, and both CRF and GABA release in the amygdala. Physiol Behav $82: 751-762$.

Davis M (2000) The role of the amygdala in conditioned and unconditioned fear and anxiety. In: The amygdala: a functional analysis (Aggleton JP, ed), pp 213-287. New York: Oxford UP.

Dong HW, Swanson LW (2004) Organization of axonal projections from the anterolateral area of the bed nuclei of the stria terminalis. J Comp Neurol 468:277-298.

Dong HW, Petrovich GD, Swanson LW (2001) Topography of projections from amygdala to bed nucleus of the stria terminalis. Brain Res Rev 38:192-246.

Fanselow MS (1980) Conditional and unconditional components of postshock freezing in rats. Pavlov J Biol Sci 15:177-182.

Fanselow MS, LeDoux JE (1999) Why we think plasticity underlying Pavlovian fear conditioning occurs in the basolateral amygdala. Neuron 23:229-232.

Fendt M, Fanselow MS (1999) The neuroanatomical and neurochemical basis of conditioned fear. Neurosci Biobehav Rev 23:743-760.

Herkenham M (1987) Mismatches between neurotransmitter and receptor 
localization in brain: observations and implications. Neuroscience 23:1-38.

Herringa RJ, Nanda SA, Hsu DT, Roseboom PH, Kalin NH (2004) The effects of acute stress on the regulation of central and basolateral amygdala CRF-binding protein gene expression. Mol Brain Res 131:17-25.

Hubbard DT, Nakashima BR, Lee I, Takahashi LK (2007) Activation of basolateral $\mathrm{CRF}_{1}$ receptors modulates the consolidation of contextual fear. Neuroscience 150:818-828.

Jahn O, Radulovic J, Stiedl O, Tezval H, Eckart K, Spiess J (2005) Corticotropin-releasing factor binding protein-a ligand trap? Mini Rev Med Chem 5:953-960.

Jasmin L, Burkey AR, Card JP, Basbaum AI (1997) Transneuronal labeling of a nociceptive pathway, the spino-(trigemino-)parabrachioamygdaloid, in the rat. J Neurosci 17:3751-3765.

Jolkkonen E, Pitkänen A (1998) Intrinsic connections of the rat amygdaloid complex: projections originating in the central nucleus. J Comp Neurol 395:53-72.

Justice NJ, Yuan ZF, Sawchenko PE, Vale W (2008) Type 1 corticotropinreleasing factor receptor expression reported in BAC transgenic mice: implications for reconciling ligand-receptor mismatch in the central corticotropin-releasing factor system. J Comp Neurol 511:479-496.

Karolyi IJ, Burrows HL, Ramesh TM, Nakajima M, Lesh JS, Seong E, Camper SA, Seasholtz AF (1999) Altered anxiety and weight gain in corticotropin-releasing hormone-binding protein-deficient mice. Proc Natl Acad Sci U S A 96:11595-11600.

Keen-Rhinehart E, Michopoulos V, Toufexis DJ, Martin EL, Nair H, Ressler KJ, Davis M, Owens MJ, Nemeroff CB, Wilson ME (2009) Continuous expression of corticotropin-releasing factor in the central nucleus of the amygdale emulates the dysregulation of the stress and reproductive axes. Mol Psychiat 14:37-50.

Kim JJ, Jung MW (2006) Neural circuits and mechanism involved in pavlovian fear conditioning: a critical review. Neurosci Biobehav Rev 30:188-202.

Kolber BJ, Roberts MS, Howell MP, Wozniak DF, Sands MS, Muglia LJ (2008) Central amygdala glucocorticoid receptor action promotes fearassociated CRH activation and conditioning. Proc Natl Acad Sci U S A 105:12004-12009.

Koo JW, Han JS, Kim JJ (2004) Selective neurotoxic lesions of basolateral and central nuclei produce differential effects on fear conditioning. J Neurosci 24:7654-7662.

LeDoux JE (2000) Emotion circuits in the brain. Annu Rev Neurosci 23:155-184.

LeDoux JE, Iwata J, Cicchetti P, Reis DJ (1988) Different projections of the central amygdaloid nucleus mediate autonomic and behavioral correlates of conditioned fear. J Neurosci 8:2517-2529.

Lee JL, Di Ciano P, Thomas KL, Everitt BJ (2005) Disrupting reconsolidation of drug memories reduces cocaine-seeking behavior. Neuron 47:795-801.

Ludwig M, Leng G (2006) Dendritic peptide release and peptide-dependent behavior. Nat Rev Neurosci 7:126-136.

Makino S, Gold PW, Schulkin J (1994) Corticosterone effects on corticotropin-releasing hormone mRNA in the central nucleus of the amygdala and the parvocellular region of the paraventricular nucleus of the hypothalamus. Brain Res 640:105-112.

Malkani S, Wallace KJ, Donley MP, Rosen JB (2004) An erg-1 (zif268) antisenseoligodeoxynucleotide infused into the amygdala disrupts fear conditioning. Learn Mem 11:617-624.

Maren S (1999) Long-term potentiation in the amygdala: a mechanism for emotional learning and memory. Trends Neurosci 22:561-567.

Maren S (2005) Building and burying fear memories in the brain. Neuroscientist 11:89-99.

McDonald AJ (1998) Cortical pathways to the mammalian amygdala. Prog Neurobiol 55:257-332.

McDonald AJ, Mascagni F (1997) Projections of the lateral entorhinal cortex to the amygdala: a Phaseolus vulgaris leucoagglutinin study in the rat. Neuroscience 77:445-459.

McIntyre CK, Miyashita T, Setlow B, Marjon KD, Steward O, Guzowski JF, McGaugh JL (2005) Memory-influencing intra-basolateral amygdala drug infusions modulate expression of Arc protein in the hippocampus. Proc Natl Acad Sci U S A 102:10718-10723.

Merali Z, McIntosh J, Kent P, Michaud D, Anisman H (1998) Aversive and appetitive events evoked the release of corticotropin-releasing hormone and bombesin-like peptides at the central nucleus of the amygdala. J Neurosci 18:4758-4766.

Merali Z, Anisman H, James JS, Kent P, Schulkin J (2008) Effects of corticosterone on corticotropin-releasing hormone and gastrin-releasing peptide release in response to an aversive stimulus in two regions of the forebrain (central nucleus of the amygdala and prefrontal cortex). Eur J Neurosci 28:165-172.

Merlo Pich E, Lorang M, Yeganeh M, Rodriguez de Fonseca F, Raber J, Koob GF, Weiss F (1995) Increase of extracellular corticotropin-releasing factor-like immunoreactivity levels in the amygdala of awake rats during restraint stress and ethanol withdrawal as measured by microdialysis. J Neurosci 15:5439-5447.

Paré D, Quirk GJ, Ledoux JE (2004) New vistas on amygdala networks in conditioned fear. J Neurophysiol 92:1-9.

Paxinos G, Watson C (1998) The rat brain in stereotaxic coordinates, Ed 4. San Diego: Academic.

Petrovich GD, Swanson LW (1997) Projections from the lateral part of the central amygdalar nucleus to the postulated fear conditioning circuit. Brain Res 763:247-254.

Pitkänen A (2000) Connectivity of the rat amygdaloid complex. In: The amygdala: a functional analysis (Aggleton JP, ed), pp 31-115. New York: Oxford UP.

Pitkänen A, Savander V, LeDoux JE (1997) Organization of intraamygdaloid circuitries in the rat: an emerging framework for understanding functions of the amygdale. Trends Neurosci 20:517-523.

Potter E, Behan DP, Linton EA, Lowry PJ, Sawchenko PE, Vale WW (1992) The central distribution of a corticotropin-releasing factor (CRF) binding protein predicts multiple sites and modes of interaction with CRF. Proc Natl Acad Sci U S A 89:4192-4196.

Radulovic J, Sydow S, Spiess J (1998) Characterization of native corticotropin-releasing factor receptor type 1 (CRFR1) in the rat and mouse central nervous system. J Neurosci Res 54:507-521.

Risbrough VB, Geyer MA, Hauger RL, Coste S, Stenzel-Poore M, Wurst W, Holsboer $\mathrm{F}$ (2009) $\mathrm{CRF}_{1}$ and $\mathrm{CRF}_{2}$ receptors are required for potentiated startle to contextual but not discrete cues. Neuropsychopharmacology 34:1494-1503.

Roozendaal B (2003) Systems mediating acute glucocorticoid effects on memory consolidation and retrieval. Prog Neuropsychopharmacol Biol Psychiatry 27:1213-1223.

Roozendaal B, Brunson KL, Holloway BL, McGaugh JL, Baram TZ (2002) Involvement of stress-released corticotropin-releasing hormone in the basolateral amygdala in regulating memory consolidation. Proc Natl Acad Sci U S A 99:13908-13913.

Roozendaal B, Schelling G, McGaugh JL (2008) Corticotropin-releasing factor in the basolateral amygdala enhances memory consolidation via an interaction with the $\beta$-adrenoceptor-cAMP pathway: dependence on glucocorticoid receptor activation. J Neurosci 28:6642-6651.

Sakanaka M, Shibasaki T, Lederis K (1986) Distribution and efferent projections of corticotropin-releasing factor-like immunoreactivity in the rat amygdaloid complex. Brain Res 382:213-238.

Sullivan GM, Apergis J, Bush DE, Johnson LR, Hou M, Ledoux JE (2004) Lesions of the bed nucleus of the stria terminalis disrupt corticosterone and freezing responses elicited by a contextual but not a specific cueconditioned fear stimulus. Neuroscience 128:7-14.

Thompson BL, Erickson K, Schulkin J, Rosen JB (2004) Corticosterone facilitates retention of contextually conditioned fear and increases CRH mRNA expression in the amygdala. Behav Brain Res 149:209-215.

Treweek JB, Jaferi A, Colago EE, Zhou P, Pickel VM (2009) Electron microscopic localization of corticotropin-releasing factor (CRF) and CRF receptor in rat and mouse central nucleus of the amygdala. J Comp Neurol 512:323-335.

Van Pett K, Viau V, Bittencourt JC, Chan RK, Li HY, Arias C, Prins GS, Perrin M, Vale W, Sawchenko PE (2000) Distribution of mRNAs encoding CRF receptors in brain and pituitary of rat and mouse. J Comp Neurol 428:191-212.

Veening JG, Swanson LW, Sawchenko PE (1984) The organization of projections from the central nucleus of the amygdala to brainstem sites involved in central autonomic regulation: a combined retrograde transportimmunohistochemical study. Brain Res 303:337-357.

Waddell J, Morris RW, Bouton ME (2006) Effects of bed nucleus of the stria terminalis lesions on conditioned anxiety: aversive conditioning with 
long-duration conditional stimuli and reinstatement of extinguished fear. Behav Neurosci 120:324-336.

Walker D, Yang Y, Ratti E, Corsi M, Trist D, Davis M (2009) Differential effects of the CRF-R1 antagonist GSK876008 on fear-potentiated, lightand CRF-enhanced startle suggest preferential involvement in sustained vs phasic threat responses. Neuropsychopharmacology 34:1533-1542.

Walker P, Carrive P (2003) Role of ventrolateral periaqueductal gray neurons in the behavioral and cardiovascular responses to contextual conditioned fear and poststress recovery. Neuroscience 116:897-912.

Watts AG, Sanchez-Watts G (1995) Region-specific regulation of neuropeptide mRNAs in rat limbic forebrain neurons by aldosterone and corticosterone. J Physiol 486:721-736.
Westphal NJ, Seasholtz AF (2006) CRH-BP: the regulation and function of a phylogenetically conserved binding protein. Front Biosci 11:1878-1891.

Wilensky AE, Schafe GE, Kristensen MP, LeDoux JE (2006) Rethinking the fear circuit: the central nucleus of the amygdala is required for the acquisition, consolidation, and expression of pavlovian fear conditioning. J Neurosci 26:12387-12396.

Wu HC, Chen KY, Lee WY, Lee EHY (1997) Antisense oligonucleotides to corticotropin-releasing factor impair memory retention and increase exploratory behavior. Neuroscience 78:147-153

Zimmerman JM, Rabinak CA, McLachlan IG, Maren S (2007) The central nucleus of the amygdala is essential for acquiring and expressing conditional fear after overtraining. Learn Mem 14:634-644. 